\title{
Effect of X-ray and artificial aging on parchment
}

\author{
Monia Vadrucci ${ }^{1, a}$, Cristina Cicero ${ }^{2}$ (D) Claudia Mazzuca $^{3}$, Fulvio Mercuri $^{4}$, \\ Mauro Missori ${ }^{5,6}$, Noemi Orazi $^{4}$, Leonardo Severini ${ }^{3}$, Ugo Zammit $^{4}$ \\ ${ }^{1}$ Particle Accelerator for Medical Application Laboratory, Italian National Agency for New Technologies, \\ Energy and Sustainable Economic Development (ENEA), Rome, Italy \\ 2 Conservation and Restoration of Cultural Heritage, Department of Literary, Philosophical and Art History \\ Studies, University of Rome "Tor Vergata", Rome, Italy \\ 3 Department of Chemical Science and Technologies, University of Rome "Tor Vergata", Rome, Italy \\ 4 Department of Industrial Engineering, University of Rome "Tor Vergata", Rome, Italy \\ 5 Institute of Complex Systems, National Research Council (CNR-ISC), Rome, Italy \\ ${ }^{6}$ Department of Physics, Sapienza University of Rome, Rome, Italy
}

\begin{abstract}
In this study, the employment of the X-ray irradiation as bioremediation method to treat parchment has been deeply investigated. In particular, the effect of the irradiation doses on the structural stability of collagen, the main constituent of parchment, has been evaluated on a series of modern parchment samples by means of different opto-thermal and spectroscopic techniques in order to obtain the dose-dependent effect of irradiation on collagen. Moreover, the long-term behavior of the irradiated parchment has been considered by analyzing the same series of samples after being hygrothermally artificially aged. Characterizations by light transmission analysis, Fourier transform infrared spectroscopy and the ultraviolet-visible-near infrared (UV-Vis-NIR) reflectance one have been performed for the identification of the radio-induced effect on the parchment structure even in a dose range much wider than the need for sterilization. The obtained results have proved the safeness of the method in the short and long term confirming the applicability of this emerging procedure.
\end{abstract}

\section{Introduction}

Parchment has been one of the most important and popular mediums for writing. It was the only writing support employed in the Western world, and its use was abandoned only after the invention of printing and the diffusion of paper that became the cheapest and more suitable support for printing (XV century). It is obtained from animal skins by peculiar manufacturing processes and, in particular, the procedure of drying through tensioning makes the parchment different from others collagen-based products such as leather or alum-tawed skin [1]. The stretching of the pelt during the drying induces a reorganization of the fiber network in the so-called dermal layer (the only one left after the treatments) producing a stable and resistant material. These peculiar features, as well as its physico-chemical properties and mechanical characteristics, are related to its complex structure and, in particular, to the conditions of the collagen fibers network that constitute it $[2,3]$.

\footnotetext{
a e-mail: monia.vadrucci@enea.it (corresponding author)
} 
As a collagen-based material, parchment undergoes inevitable degradation phenomena over time mainly due to deteriorating agents present in the material or in the preservation environment such as acid substances and humidity (acid hydrolysis), oxidizing agents and atmospheric $\mathrm{O}_{2}$ (oxidation), microorganisms (bio-deterioration), or light (photo-degradation by UV radiation). All these processes give a synergistic effect that leads to changes in the crystallinity of the collagen matrix and a progressive shortening of the polymer chains through depolymerization, with a ruinous loss of integrity of the parchment [4-6].

Among the cited phenomena, the parchment biodeterioration problem is largely studied in the conservation field of the collagen-based artifacts and more generally of the cultural heritage. Parchment damage due to the microbiological burden is harmful also for the health of librarians, archivists and the scholars [7-13].

Currently, despite it is largely abandoned, in some countries the most common method used to ensure the sterilization of library materials is the treatment with ethylene oxide, in spite of previous studies have shown that it makes collagen more prone to be attacked by mold [14], as well as being toxic to the humans and the natural environment.

An optional technique is the use of irradiation. Since the 1960s, thanks to their high penetration, gamma rays have been applied in the disinfection treatment of large quantities of library and archive artifacts [15-24]. A promising alternative, more accessible than gamma rays, since the high and stringent security measures relating to access to nuclear plants and radioactive sources are not necessary, is the use of $\mathrm{X}$ radiation produced by the conversion of accelerated electron beams.

In previous works dealing with the microbiological aspects of the pest system and studying the effectiveness of different radiation absorbed doses in the elimination of typical bacterial colonies [25-28], promising results have been obtained. The decontamination of the microbiologically infected collagen-based materials, such as parchment and leather, through X-rays obtained in this way takes place by exploiting a process requiring short time and low radiation dose with respect to the use of gamma rays.

This is a very important aspect not only for the cost and for the environmental economy of the treatments, especially for huge quantities of objects, but also because it significantly limits the post-irradiation degradation effects on collagen within the parchment.

Our approach has allowed the optimization of the irradiation conditions to ensure the effectiveness of microbiological decontamination of the parchment and to ensure its own safety regarding the protection of the intrinsic properties of the parchment as writing support $[26,27]$. The results obtained showed also that the complete removal of the biodegradation from the parchment is reached carrying out single treatments at $350 \mathrm{~Gy}$ of total dose.

This work regards the investigation performed to determine the stability over time of parchments subjected to X-ray beams produced by the REX (Removable Electrons to Xrays) machine, a facility available at the ENEA laboratories of Frascati (Rome) [26, 29] to show how the fast irradiation treatments preserve the artifact characteristics without further deterioration of the parchment. The long-term stability was analyzed by artificially aging the samples in an environment with severe hygrothermal conditions. In this first preliminary work, the study of the long-term stability is carried out in parchment where the deterioration was caused only by the sterilizing irradiation process, where no effects associated with the presence of biological deteriogenic agents are at the moment considered. 


\section{Materials and methods}

\subsection{Sample preparation and irradiation}

The bioremediation experiments have been carried out on a not written modern parchment prepared according to the traditional procedure using goat skin. Squares pieces of $20 \times$ $20 \mathrm{~mm}^{2}$ were cut for the optical and spectroscopic characterization considering the typical intrinsic inhomogeneity of the primary material being animal origin and handmade. This is a very important aspect that must be underlined as a starting point for the carried out analyses as the case study we have dealt with is certainly representative of the widest typology of parchment objects of interest for conservation and restoration.

In the present study, we want to investigate the response of the parchment support to extreme conditions of high-dose irradiation to characterize the peculiarity of the X-ray beam proposed as a safe intervention method for the conservation of the artefacts. Therefore, the post-irradiation control and measurements were carried out on the samples processed up to 5000 Gy.

In order to evaluate the long-term effect of the irradiation on the collagen molecule, after the bioremediation treatment the parchment samples have been artificially aged in an environment with severe automatically controlled temperature and humidity conditions ( $T$ $=80{ }^{\circ} \mathrm{C}$ and $\mathrm{RH}=80 \%$ ). The samples were treated for 32 days, a duration which previous studies [30] showed producing the maximum aging effect for such conditions. All the samples have been analyzed by the characterization techniques described in Sect. 2.2 before and after the aging treatment.

The irradiation tests were carried out by the REX (Removable Electrons to X-ray) facility $[26,29]$, working with an X-ray source based on an electron accelerator designed and manufactured in ENEA for clinical and industrial purposes. The electrons are accelerated up to an energy of $5 \mathrm{MeV}$ by a Linac, a device using high-frequency electromagnetic waves (about $3000 \mathrm{MHz}$ ) to accelerate charged particles, and operated in a micropulsed regime.

The accelerated electrons hit a removable target, built with a high atomic number material, thick enough to stop them. X radiation emerges from the conversion head characterized by a continuous distribution of radiation that becomes more intense and moves toward higher frequencies with the increase in the energy of the bombarding electrons. The single characteristic emission lines are superimposed on the continuous spectrum: for the specific application of this source in the treatment of materials of cultural heritage interest, this is the characteristic emission of tungsten $(Z=74)$.

The X-ray conversion target is inserted in a conical lead collimator (external diameter $30 \mathrm{~mm}$ ) from which the photons come out with a circular spot that spreads into the irradiation chamber in the air. The process control procedures have been defined according to the capability to accurately deliver the specified dose to the sample as the success of radiation treatment of cultural heritage objects depends mainly on it.

Figure 1 reports the digitized image of the radiochromic film (GAFchromic films with lateral dimensions of $6.7 \times 7.3 \mathrm{~cm}^{2}$ ) used to verify position and homogeneity of X-ray beam in these irradiation campaigns. The dark halo $(5.5 \mathrm{~cm}$ diameter $)$ is the radiation footprint: it has a $98 \%$ homogeneity on a circular ROI larger than $3 \mathrm{~cm}$ at the beam exit. The figure shows also the enlargement in-air of the beam beyond the last filter in front of the source.

A plane parallel ionization chamber (model PPC05 from IBA), moved by a remote handling system and connected to a reference class electrometer (model Dose 1 from IBAWellhofer-Scanditronix), is used to measure the real-time dose rate in the $410 \times 810 \times 400$ $\mathrm{mm}^{3}$ in-air irradiation volume (shielded by lead walls). This online active sensor is placed 
Fig. 1 X-ray beam characteristics. Radiochromic EBT3 film impressed by the $\mathrm{X}$-ray beam of the REX machine. A in air X-rays propagation verification for the selected operational conditions: film exposed in the parallel geometry; B size and homogeneity verification of the $\mathrm{X}$-Rays spot at the selected distance: film is exposed orthogonally to the beam direction with the application of a diaphragm
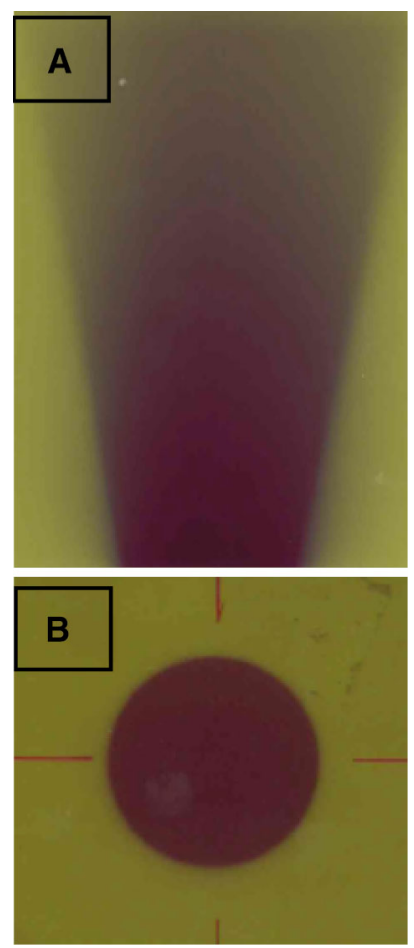

at the bottom of the samples stack. The treatment dose rate is operated at $0.35 \mathrm{mGy} / \mathrm{s}$, with an adsorbed dose error less of $0.5 \%$. The temperature of the irradiated objects is monitored with an infrared thermometer.

The use of the entire band produces the sterilization effect much more efficiently than with monochromatic gamma sources. Although the contribution of the various energy regions to the final results could not yet be detailed, the region with energy below $1.17-1.33 \mathrm{MeV}$ is, presumably, the most efficient.

\subsection{Characterization techniques}

\subsubsection{FTIR-ATR spectroscopy}

FTIR-ATR spectroscopy has been employed in order to characterize the chemical structure of the parchment. It is one of the most powerful non-destructive methods for monitoring changes in the proteins secondary structures, due, for example, to denaturation [31-33].

FTIR-ATR measurements were used to investigate, in a non-destructive way, the effects of parchment deterioration induced by X-ray irradiation and artificial aging, at molecular level. Given the high sensitivity to conformation, the information on the denaturation of parchment proteins is provided analyzing the intensities and the relative displacements of the Amide I and Amide II bands on the collected infrared spectrum. FTIR spectra of proteins provide global structural information and consist of several infrared-active amide vibrational modes, among which the Amide I and II modes are particularly sensitive to the nature of secondary structure $[34,35]$ and allow to monitor its changes, due to denaturation, hydrolysis or oxidation [31-33, $36,37]$. The Amide I band $\left(1700-1600 \mathrm{~cm}^{-1}\right)$ is primarily associated with the $\mathrm{C}=\mathrm{O}$ stretching 
vibration belonging to polypeptide chain, and different secondary structures produce Amide I band at different frequencies. The Amide II band (1570-1500 $\left.\mathrm{cm}^{-1}\right)$, on the other hand, is originated from $\mathrm{NH}$ in-plane bending, $\mathrm{CN}$ stretching and to a lesser extent, from other vibrations of the amide group [38-41].

Experimentally, the FTIR absorption spectra were acquired with the Thermo-Scientific instrument (model Is50) (Thermo Scientific Inc., Madison WI) in Attenuated Total Reflectance (ATR) mode using a single reflection diamond cell. Spectra were recorded from 4000 to $750 \mathrm{~cm}^{-1}$, averaging over 32 scans with a resolution of $2 \mathrm{~cm}^{-1}$.

\subsubsection{UV-Vis-NIR reflectance spectroscopy}

UV-Vis-NIR diffuse reflectance spectra of parchment samples were measured at a temperature of about $23{ }^{\circ} \mathrm{C}$ by using a set-up from Avantes BV (The Netherlands) [42]. The UV-Vis-NIR source employed in the set-up is a combined deuterium-halogen AvaLightDH-S-BAL light source. This light source is connected by an $800-\mu$ m-diameter optical fiber to a 30-mm-diameter Spectralon-coated integrating sphere (model AvaSphere-30-REFL). The integrating sphere is used to illuminate the samples and collect the radiation diffusely reflected from the parchment surface from all angles. Its sample port is $6 \mathrm{~mm}$ in diameter. From the integrating sphere, radiation is sent by a $600-\mu \mathrm{m}$-diameter optical fiber to an AvaSpec-2048 $\times 14$-USB2 spectrometer equipped with a $2048 \times 14$ pixels CCD detector. The spectrometer diffraction grating allows the acquisition of spectra in the $248-1050 \mathrm{~nm}$ range with a constant $2.4 \mathrm{~nm}$ spectral resolution. Data acquisition is controlled by a personal computer. Two areas $6 \mathrm{~mm}$ in diameter were measured for each parchment sample. Each reflectance spectrum was obtained by averaging 5 acquisitions lasting 5 seconds each. Since parchment samples have a finite thickness, two sets of spectra were measured. The first one $\left(R_{w}\right)$ is obtained with the parchment samples placed over a white background (i.e., with reflectance close to 1$)$; the second one $\left(R_{b}\right)$ is obtained with the parchment samples placed over a black background (i.e., with reflectance close to 0 ). The reflectance of the background materials ( $R_{w b}$ and $R_{b b}$ for white and black, respectively) was measured separately. All measured spectra were normalized to a factory calibrated Spectralon diffuse reflectance reference standard (Labsphere, USA), allowing the absolute reflectance to be recovered.

Once $R_{w}, R_{b}, R_{w b}$, and $R_{b b}$ are measured, the Kubelka-Munk (KM) theory [43-45] allows to calculate the reflectance $R_{\infty}$ that would have a layer of infinite thickness of the parchment samples:

$$
R_{\infty}=a-\sqrt{a^{2}-1}
$$

where

$$
a=\frac{\left(R_{w b}-R_{b b}\right)\left(1-R_{w} R_{b}\right)-\left(R_{w}-R_{b}\right)\left(1+R_{w b} R_{b b}\right)}{2\left(R_{b} R_{w b}-R_{w} R_{b b}\right)}
$$

Once $R_{\infty}$ is determined, it is possible to recover the KM absorbance $\left(A_{\mathrm{KM}}\right)$, which is the ratio of the phenomenological absorption $K$ and scattering $S$ coefficients [46]:

$$
A_{\mathrm{KM}}=\frac{K}{S}=\frac{\varepsilon c}{S}=\frac{\left(1-R_{\infty}\right)^{2}}{2 R_{\infty}}
$$

$A_{\mathrm{KM}}$ is a pure number, which depends on the concentration, $c$, of a specific compound within the sample and on its molar absorptivity $\varepsilon$. For optically inhomogeneous media such as parchment, which is made of a collection of non-uniformly sized rough-surfaced collagen fibers, $S$ varies smoothly with the wavelength and can be considered constant within the 
studied UV-Vis-NIR spectral range [45]. In addition, $c$ is proportional to the volume fraction of collagen fibers within the samples and, therefore, to the density of the samples [47].

\subsubsection{LTA}

Hydrothermal stability can be related to the level of deterioration of collagen fibers [48]. It is typically investigated by determining a characteristic temperature associated to the denaturation process that takes place when the collagen fibers are heated in water. A number of techniques, like MHT, DSC, ASC [30, 49, 50] can be used to investigate the hydrothermal denaturation process. Among them, light transmission analysis (LTA) has proved to be a reliable technique for determining the hydrothermal denaturation temperature $\left(T_{\mathrm{d}}\right)$ of collagen structured in parchment fibers. The $T_{\mathrm{d}}$ value depends on the degree of integrity of the collagen whose deterioration produces a decrease in the $T_{\mathrm{d}}$ value [30]. Therefore, when the sample is artificially deteriorated with specific treatments, the amount of damage produced can be monitored by measuring the $T_{\mathrm{d}}$ downshift. In this work, $T_{\mathrm{d}}$ has been measured as a function of the dose.

In the LTA denaturation characterization, the light transmitted through a suspension of parchment fibers in water is analyzed while their hydrothermal denaturation process is induced by increasing the specimen temperature at a constant rate of about $0.8{ }^{\circ} \mathrm{C} / \mathrm{min}$, from room temperature up to $90^{\circ} \mathrm{C}$. The light source is provided by a He-Ne laser beam that crosses a $0.1-\mathrm{mm}$-thick suspension while the LTA signal, $L$, is generated by a photodiode onto which the light emerging from the cell and collected by a lens is focused. The LTA experimental setup is also integrated by a polarization microscopy facility so that inspection of the sample texture changes induced by the denaturation process can also be carried out.

During the denaturation process, the collagen molecules that form the parchment fibers lose their characteristic triple helix shape transforming their structure from an ordered hierarchical to an amorphous one, characterized by a considerably smaller capability to scatter the light of the probe beam. This causes an increase in the transmission signal which is larger the greater the quantity of material that is transformed at that given temperature. This aspect is well characterized by the LTA signal derivative with respect to temperature whose curve shows a peak at the temperature value where the maximum hydrothermal denaturation activity takes place, considered as the denaturation temperature $T_{\mathrm{d}}$.

It is worth noting that the hydrothermal denaturation of the collagen is mainly associated with the breaking of the molecules hydrogen bonds induced by the heating of the sample. In damaged collagen, the molecular bonding is weaker than in a sound one and a smaller amount of thermal energy is required to denaturate it. Consequently, the denaturation will take place at a lower temperature.

\section{Results}

\subsection{FTIR}

The results obtained by means of ATR-FTIR spectroscopy do not reveal any deterioration process (denaturation or hydrolysis) attributable to irradiation procedure on collagen molecules. As shown by the data reported in Fig. 2, indeed, the ratio values between intensity of the Amide I and II bands do not change after the irradiation treatment indicating that hydrolysis of the collagen does not occur. At the same time, the relative distance between Amide I and II bands does not change significantly after the same treatment (it is $88 \mathrm{~cm}^{-1}$ in every 


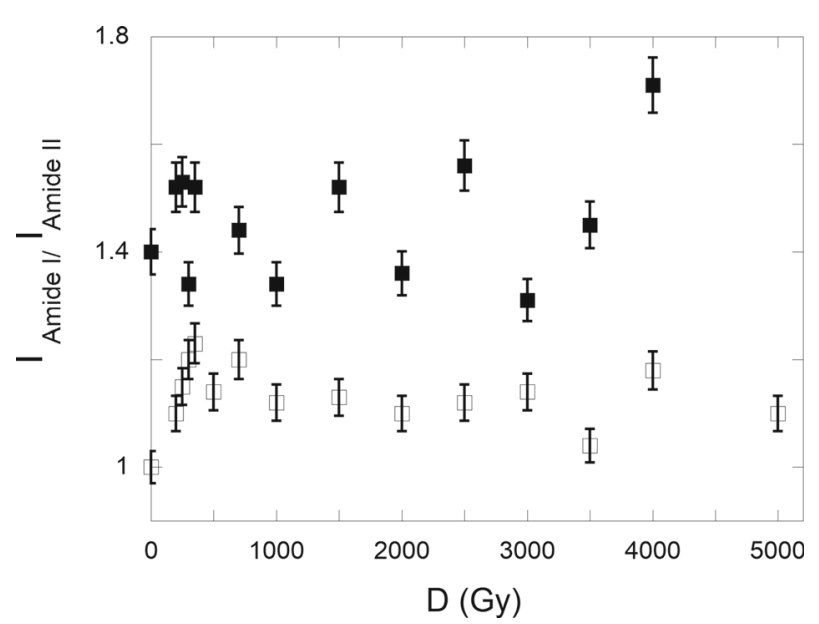

Fig. 2 FTIR data of the ratio between the intensities of the Amide I and II bands. Not aged (empty squares) and aged (full squares) parchment samples

sample; see Fig. 3), demonstrating that no denaturation (gelatinization) process took place [51-53]. The most noticeable effect of samples X-ray irradiation is oxidation, shown by the appearance of the bands at about $1745 \mathrm{~cm}^{-1}$ due to the formation of carboxyl group and that at $1795 \mathrm{~cm}^{-1}$, associated with the $\mathrm{C}=\mathrm{O}$ stretching of acyl halide, probably due to irradiation treatment (Fig. 3). The presence of the last compound is attributable to radical reactions involving chlorine probably derived from calcination baths and/or bleaching, treatments performed during the parchment manufacturing process [54]. The intensities of these last bands due to oxidation are not X-ray irradiation dose dependent, as expected by the inner complexity of the oxidation processes involving also radical ions [55]. In accordance with LTA results presented below, FTIR spectra show independent trends for the two processes (oxidation and hydrolysis due to artificial aging) just described.

\subsection{UV-Vis-NIR reflectance spectroscopy}

The non-irradiated parchment sample shows a maximum of the $A_{\mathrm{KM}}$ absorbance in the UV side of the measured spectral range, followed by an evident shoulder at about $280 \mathrm{~nm}$, a descent with a shoulder at about $330 \mathrm{~nm}$ and a tail in the Vis range, up to about $500 \mathrm{~nm}$, as shown in Fig. 4a. From 500 up to $1050 \mathrm{~nm}$, the samples show negligible values of absorbance. The spectral features observed in these ranges have been identified as due to the $\pi \rightarrow \pi^{*}$ and $n \rightarrow \pi *$ electronic transition of $\mathrm{C}=\mathrm{O}, \mathrm{NH}$ and $\mathrm{CONH}$ groups in collagen molecules $[49,56]$.

These spectral features are maintained in non-aged parchment samples irradiated with increasing X-rays doses (Fig. 4a). Overall, only small $A_{\mathrm{KM}}$ intensity changes are observed within the measured spectral range. In order to obtain a quantitative evaluation of these intensity changes, the integrals of $A_{\mathrm{KM}}$ were calculated in the range $250-600 \mathrm{~nm}$ for all irradiation doses. Results are shown in Fig. 5 (empty symbols). The integrals of the absorbance are overall constant up to the irradiated dose of $5000 \mathrm{~Gy}$, and only random changes are observed from one sample to another. The extent of these changes is at most $\pm 15 \%$ of the mean value, a value compatible to the relative uncertainty of the measured density of the parchment samples $(0.74 \pm 0.11) \mathrm{g} / \mathrm{cm}^{3}$. 

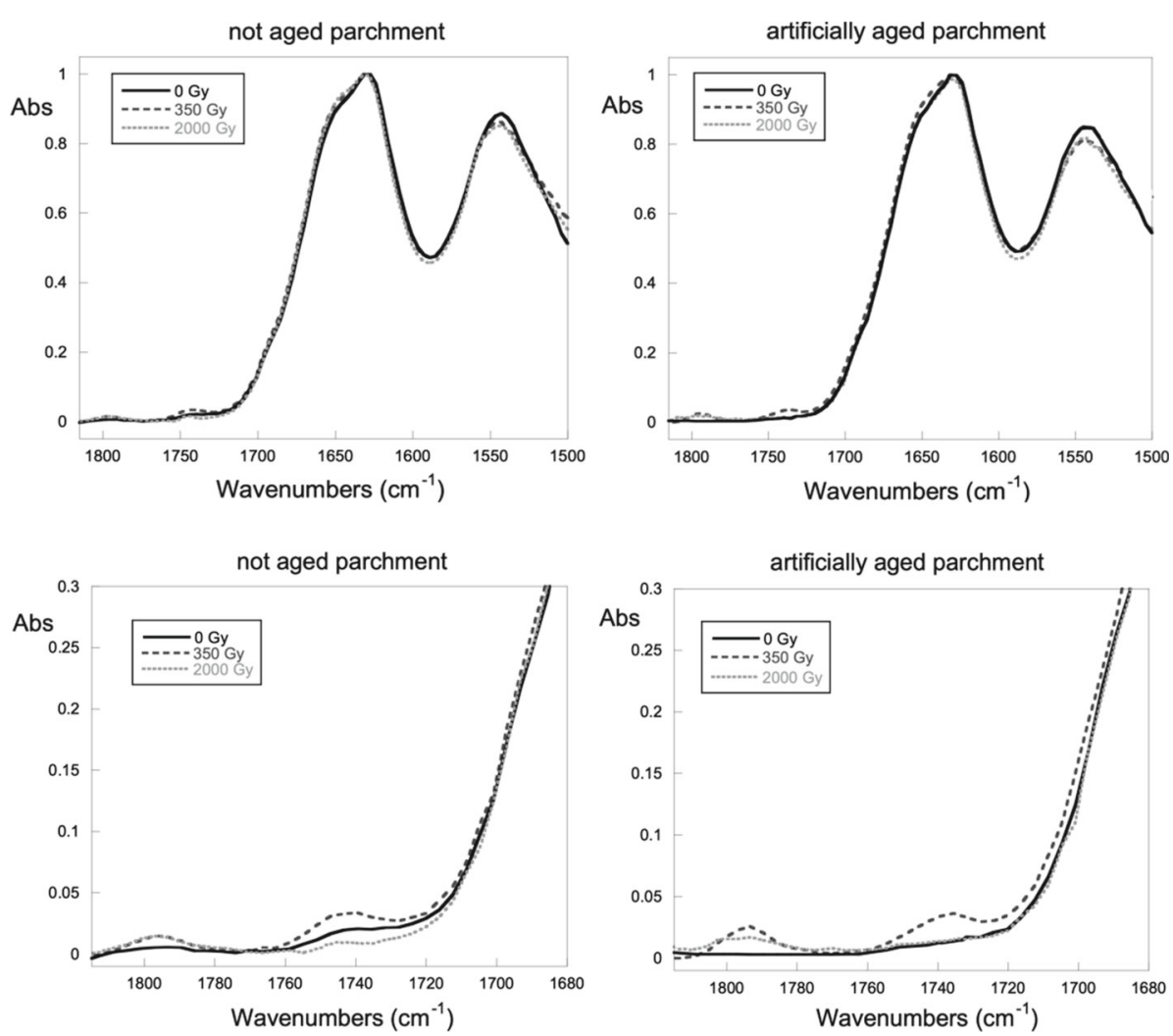

Fig. 3 FTIR spectra, before and after artificial aging. Upper panel: the Amide I and Amide II region of not irradiated sample (full line), of parchment irradiated with a dose of $350 \mathrm{~Gy}$ (dashed line) and with a dose of 2000 Gy (dotted line). Lower panel: in the $1815-1680 \mathrm{~cm}^{-1}$ region of not irradiated sample (full line), of parchment irradiated with a dose of $350 \mathrm{~Gy}$ (dashed line) and with a dose of $2000 \mathrm{~Gy}$ (dotted line)

After aging, a similar spectral behavior is observed with the difference that the shoulder at about $280 \mathrm{~nm}$ is now less evident and that overall the $A_{\mathrm{KM}}$ absorbance shows higher values (Fig. 4b). Difference spectra obtained by subtracting the spectra measured after the artificial aging from those measured before show the presence of a broad band with a maximum at about $300 \mathrm{~nm}$ (Fig. 4c).

The presence of this spectral feature was already reported for ancient naturally aged parchments as a bathochromic shift of the bands at about $280 \mathrm{~nm}$ assigned to -CONHgroups as compared to unaged samples. The band was attributed to some structures with extended conjugation resulting most likely by oxidation of organic acids existent in the parchment in agreement with FTIR results. Our measurements for the first time reveal that this UV band develops even for artificially aged parchment also confirming the goodness of the used aging procedure. In addition, this band extending up to a wavelength of $500 \mathrm{~nm}$ can be considered the responsible for the yellowing of parchment with age.

The integrals of $A_{\mathrm{KM}}$ after aging calculated in the range $250-600 \mathrm{~nm}$ are overall constant up to the irradiated dose of $4000 \mathrm{~Gy}$ and only random changes are observed from one sample to another. The extent of these changes is still compatible to the relative uncertainty of the density of the parchment samples (Fig. 5, filled symbols). 


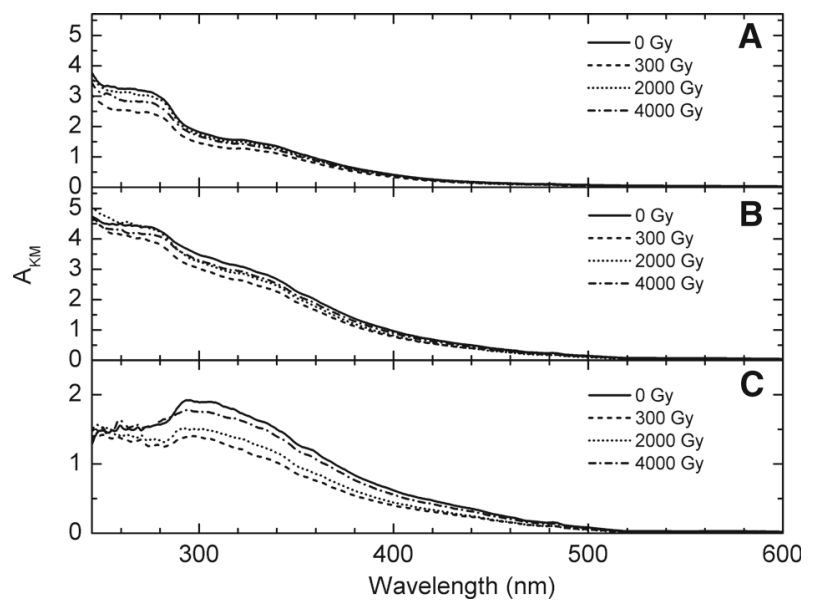

Fig. 4 Kubelka-Munk absorbance $\left(A_{\mathrm{KM}}\right)$ of irradiated parchment samples as a function of wavelength. Panel A: $A_{\mathrm{KM}}$ spectra before aging; Panel $\mathrm{B}: A_{\mathrm{KM}}$ spectra after aging; Panel C: $A_{\mathrm{KM}}$ difference spectra obtained by subtracting the spectra measured after the artificial aging from those measured before

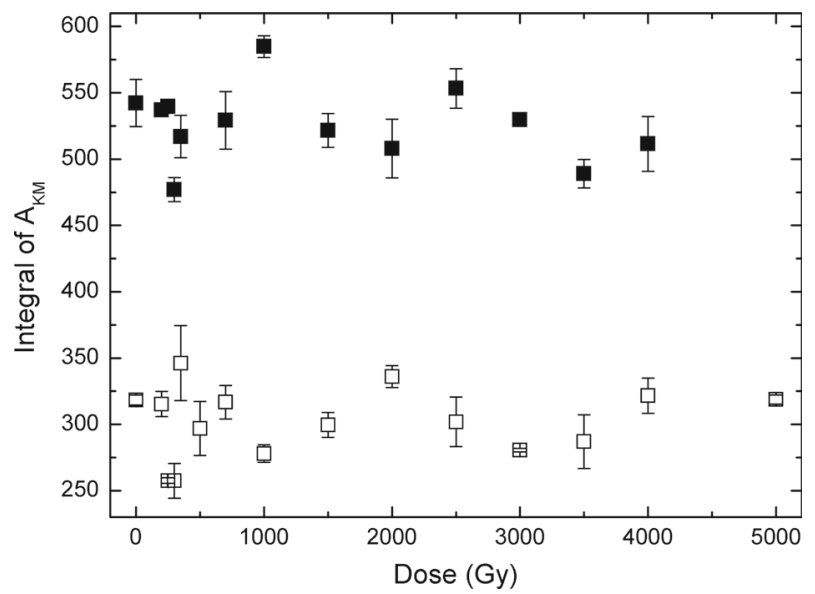

Fig. 5 Integrals of Kubelka-Munk absorbance $\left(A_{\mathrm{KM}}\right)$ of irradiated parchment samples as a function of the dose. $A_{\mathrm{KM}}$ absorbance integral in the range $250-600 \mathrm{~nm}$ : before aging (empty symbols) and after aging (filled symbols). The error bars indicate the difference of the two measurements made on each parchment sample

\subsection{LTA}

In Fig. 6 the $T_{\mathrm{d}}$ behavior is reported for parchment samples exposed to increasing irradiation dose $D$ (empty symbols). In the graph, the behavior obtained with the same irradiated samples after treating them by a 32 days long accelerated aging is also shown (filled symbols).

Both the sets of $T_{\mathrm{d}}$ values obtained as a function of $D$ show a low dose regime characterized by approximately constant $T_{\mathrm{d}}$ value, highlighted by the horizontal lines in the graph, followed, for larger doses, by a decay regime characterized by an initial substantial decrease of the $T_{\mathrm{d}}$ values that tend to stabilize at a very large doses $(D>5000 \mathrm{~Gy})$. 


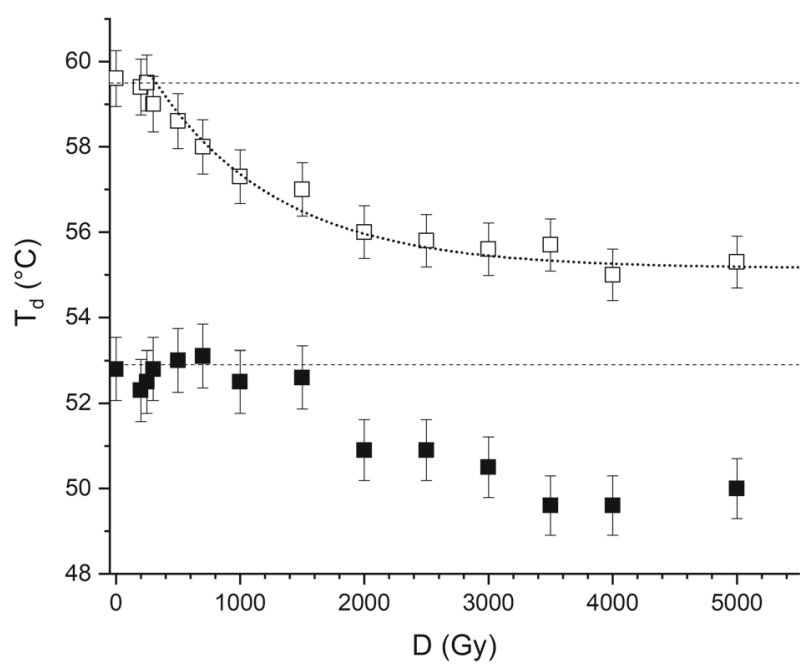

Fig. 6 Parchment denaturation temperature measured by LTA. $T_{\mathrm{d}}$ as a function of the irradiation dose. Empty symbols refer to unaged samples. Filled symbols refer to aged samples

By indicating with $D_{C}$ the dose crossing value between the two regimes, the $T_{\mathrm{d}}$ vs $D$ decay can be well described by the following exponential dependence:

$$
T_{\mathrm{d}}(D)=\left(T_{0}-T_{L}\right) e^{-\lambda(D-D c)}+T_{L}
$$

where $T_{0}$ and $T_{L}$ indicate the denaturation temperature of the non-irradiated sample and the one at which $T_{\mathrm{d}}$ tends to saturate for samples treated with very large doses, respectively, while the quantity $\lambda$ is equivalent to an effective decay coefficient of the hydrothermal stability that characterizes the sensitivity of the parchment stability to the delivered dose under the present irradiation conditions. Given the above definitions, $\Delta T=\left(T_{0}-T_{L}\right)$ represents the maximum hydrothermal stability variation that can be produced by a specific deterioration treatment, $\lambda$ its deterioration effectiveness and $D_{C}$ the threshold below which no substantial effect can be detected by the technique.

It is worth noting that if one looks at experimental data of the unaged samples reported in Fig. $6, T_{\mathrm{d}}$ does not show appreciable variations for doses up to $300 \mathrm{~Gy}$, consistently with the results of earlier investigation [26]. In the limit of the given uncertainty, from dose values equal or larger than about $500 \mathrm{~Gy}$ a crossing from the constant initial $T_{\mathrm{d}}$ value of about $59.5{ }^{\circ} \mathrm{C}$ to a regime of decreasing values that tends to saturate approaching a temperature value of about $55.2{ }^{\circ} \mathrm{C}$, can be observed. Based on this, if we assign the values $T_{0}=59.5{ }^{\circ} \mathrm{C}$, $T_{L}=55.2{ }^{\circ} \mathrm{C}$ and $D_{C}=300 \mathrm{~Gy}$ to the quantities appearing in the expression (1), the dotted curve reported in the graph is obtained by assuming the value $\lambda=10^{-3} \mathrm{~Gy}^{-1}$ for the decay coefficient of the hydrothermal stability.

In Fig. 6, the dose dependence of $T_{\mathrm{d}}$ is shown also for the irradiated samples that were subsequently artificially aged. The results point out that the hydrolysis associated with the induced aging produced a general additional reduction of the hydrothermal stability for all the previously irradiated samples. Moreover, it appears that the $T_{\mathrm{d}}$ value of the irradiated and aged samples does not vary substantially for irradiation doses smaller than $D$ values of approximately $1500 \mathrm{~Gy}$, while a progressive additional lowering is observed for larger doses. It thus appears that the irradiation and artificial aging effects on the hydrothermal stability 
accumulate and add up once extensive and complex enough damage in the parchment collagen structure is produced at the larger irradiation doses.

\section{Discussion}

\subsection{Unaged irradiated parchment}

The reference studies of the radiation induced effects on parchment refer only to the use of gamma rays, and the analysis of texture, color, mechanical properties and thermal stability was carried out on very different samples in terms of nature and manufacturing process. The characterizations highlight major difficulties due to the intrinsic non-uniformity of the material and crafts. In general, there is no systematic investigation approach and in particular, there are no specific studies aimed at understanding the effects induced by radiation at the molecular level in a dose range smaller than $5 \mathrm{kGy}$. This can be related to the fact that despite the intrinsic differences between the measured samples, the gamma radiation absorbed below $10 \mathrm{kGy}$, with a large emission rate, does not generate consequences on the hardness and elasticity of the material and it is therefore considered harmless for the new parchment [57] as well as for the naturally aged one [24].

It is worth noting that the results reported and discussed in this paper refer to samples irradiated with radiations belonging to a different spectral range that cannot be directly compared to the above-mentioned ones and quite different effects may be expected. On the other hand, it must be remarked that, up to now, no systematic study based on X-ray irradiation is available in the literature.

The results obtained with the FTIR technique and described in paragraph 2 indicate that the sterilization treatment does not generate denaturation or hydrolysis processes of the collagen (the ratio of the intensities of the Amide I and II bands remains constant) neither gelatinization (the relative distance between the Amide I and II bands remains substantially unchanged). However, FTIR spectra reveal the presence of oxidation processes triggered by the high radiation doses (specifically $2000 \mathrm{~Gy}$, an order of magnitude larger than the dose level necessary to decontaminate the support) and caused by production of radicals.

Similar results are obtained by UV-Vis-NIR spectroscopy where no significant absorbance variation is measured as the radiation dose increases. The spectral features of non-irradiated sample, taken as a reference, do not show significant changes in the range of irradiation doses.

On the other hand, the LTA data do show a dose dependence for X-ray doses $\geq 500 \mathrm{~Gy}$ : displaying a decrease in the parchment denaturation temperature of up to about $4{ }^{\circ} \mathrm{C}$, as the irradiation dose increases. These last observations are consistent with the morphological analyses carried out by SEM and AFM [27]. Both the SEM micrographs and the AFM topographic images showed the typical ordered fibrillar network of a parchment in good condition, recognizable in the samples treated with X-ray doses up to $500 \mathrm{~Gy}$ : the fibrils are grouped in aligned and non-discontinuous bundles. As the radiation treatment dose increases, above $700 \mathrm{~Gy}$, the triggering of a first degradation effect by the radiation is identified from the micrographs.

Namely, a size reduction of the molecular bundles can be observed as the amount of absorbed radiation energy increases. The altered wavy appearance of the fibers reflects the beginning of the deterioration process of the collagen matrix ordered structure. The mechanical stress measurement reveals a decrease in molecular cohesion induced by the irradiation 
and supports the indication that the collagen hierarchical structure becomes more fragile and therefore softer as the X-rays dose increases.

All the reported characterizations of the irradiated parchment indicate that up to about $500 \mathrm{~Gy}$ the hierarchical structure of collagen is able to resist the stress generated by the radiation and the interaction concerns the portion of collagen distributed in the fibrils outer sheath which retains its properties.

For X-ray doses exceeding $500 \mathrm{~Gy}$, the damage becomes relevant also in the innermost molecular portions and starts altering the native collagen located in the fibrils central regions. This phenomenon generates a deformation of the fibers which results to be not detectable by means of conventional spectroscopic techniques and thus it is not expected to induce a severe structural alteration in the collagen fibers. The supra-macromolecular structure remains intact with a stiffening of the reticular layer revealed by the Young's modulus measurement.

\subsection{Parchment irradiated and artificially aged.}

The aging effect on the collagen molecules within the parchment has been reported in literature obtained by thermal analysis studies complemented by SEM microscopy and both FTIR and UV-Vis-NIR spectroscopy, although no parchment NIR spectra report is available but only NIR spectra concerning separately water and proteins to be used for comparative purpose.

Heating at $80{ }^{\circ} \mathrm{C}$ in almost dry conditions (10\% of relative humidity in [58] but the literature reports studies carried out up to $220^{\circ} \mathrm{C}$ for example in [59]) produces large fused areas and cracks in the outer molecular layer that loses its compactness while maintaining the underlying fibrous network intact. This effect is due to the weakening of the hydrogen bonds whose primary cause is the oxidation of the outer sheath of the molecule. The consequence of this aging process on the parchment denaturation temperature is a progressive decrease with the treatment time, reflecting the progressive collagen molecule deterioration.

For aging in conditions of large relative humidity (80\%), there is an increase in the free water content within the matrix. This increases the inter-fibrillar spacing and generates a more unstable phase $[49,50]$.

The FTIR spectra obtained on irradiated and artificially aged parchment samples show a major difference from those irradiated but not aged, i.e. the additional aging treatment hydrolyzes the collagen molecules. The analysis reveals that the two subsequent processes, which the parchment was subject to, seem to produce damage independently from one another as indicated by the FTIR spectra (Fig. 2).

Furthermore, hygrothermal artificial aging is able to modify the UV-Vis-NIR spectra through the formation of a broad spectral band centered at about $300 \mathrm{~nm}$. The intensity of this band is, however, not correlated to the irradiated dose even for artificially aged samples. This behavior indicates that the sterilization treatment does not generate changes in the optical properties of the parchment for all employed doses in both the non-aged and artificial aged samples.

Quite different are the results displayed by the LTA data. They show a clear dose dependence for both the unaged and aged irradiated samples. For the irradiated non-aged samples, a detectable change in the properties of the collagen structure can be observed for doses larger than $500 \mathrm{~Gy}$, while, for those which were also aged after the irradiation, a clear dose dependence of the denaturation temperature, related to changes in the properties of the collagen structure, emerges only for doses exceeding $1500 \mathrm{~Gy}$.

Accordingly, it may be thought that the irradiation doses between 500 and 1500 Gy produce non-substantial modifications of the native collagen and a population of heterogeneous 
molecules is generated, similarly to what occurs in UV-associated photoaging processes [60]. In particular, it may occur that the penetration capability and the interaction length of the used $\mathrm{X}$-rays are such that up to the irradiation dose of $1500 \mathrm{~Gy}$, only small, random and discontinuous changes in the fibrillar structure of the collagen triple helix are induced, producing no substantial alteration of the triple helix organization and with the average molecular length remaining basically the same as in the non-irradiated samples, as suggested by the FTIR results. The degradation induced by the artificial aging process on this partially damaged phase of the parchment is more severe than that generated by the irradiation alone, inducing an additional lowering of the thermal stability to a level which turns out to be independent of the irradiation dose up to $1500 \mathrm{~Gy}$. For larger doses, a presumed more extensive and complex damage produced by the radiations provides the conditions to make the deterioration associated with the hydrolysis more effective inducing a greater additional decrease in the parchment collagen structure stability.

Finally, it is worthwhile to point out the LTA technique turned out to be the only optical probing technique sensitive enough to detect systematic dose dependent effects of the collagen deterioration. This is possibly due to the fact that the LTA measurements in some way probe the energy associated with the collagen structure in water. It may in fact occur that the radiation damage random breaks some of the bonds to the extent of locally weakening the collagen structure without altering it substantially. This is reflected in the fact that the spectroscopic techniques do not detect any change while LTA, by monitoring the denaturation temperature, can detect a reduction of the general strength of the structure.

It must be finally remarked that, as stated earlier on, the present study has only considered parchment samples where the initial deterioration was caused exclusively by the sterilizing irradiation process, and no effects associated with the presence of biological deteriogenic agents is for the moment considered. The results obtained here can be used as general information concerning the extent of the damage introduction in the dose range where the radiation successfully sterilizes the biological agents and will be useful for future studies. It is in fact planned to shortly investigate also the cases where biologically induced damage is also present in the irradiated and aged samples, and also study the case where the biological and irradiation deterioration effects will be analyzed in initially partially aged samples.

\section{Conclusions}

The X-ray treatment has been shown to be an adequate contrast agent of the main biological threats of the parchment (specific bacterial colonies isolated in vivo) which is a writing support of high importance for the cultural heritage.

With respect to the ionizing radiation treatment proposed in the literature, in this work we presented the recent improvement of a new sterilization treatment delivered performed by Xrays produced by a light and compact machine allowing the effectiveness of decontamination at dose levels contained below $1 \mathrm{kGy}$. In particular, this study dealt with characterization of the possible changes undergone by the parchment subjected to the combined action of radiation and aging performed through LTA analysis and FTIR, UV-Vis-NIR spectroscopy. The achieved results lead to a possible understanding of the phenomenon occurring on the parchment irradiated with doses between 500 Gy for unaged samples and 1500 Gy for the aged one's. Our results indicate that $\mathrm{X}$ rays can mainly produce random and discontinuous changes in the fibrillar structure of the collagen, most likely by the breaking of some hydrogen bonds between collagen fibrils, but no substantial alteration of the triple helix organization. For doses up to $500 \mathrm{~Gy}$ for unaged samples and $1500 \mathrm{~Gy}$ for aged samples, the number 
of broken hydrogen bonds is so low that collagen fibrillary structure is able to maintain its stability even when exposed to liquid water in the LTA measurements. The alteration thus remains below a critical level which appears to be overcome with a deeper modification in the samples treated with doses above $1500 \mathrm{~Gy}$ which also suffer damage from aging.

In any case, the carried out analyses have made it clear that the sterilization and biodegradation removal process operated with $\mathrm{X}$-ray beams is a safe treatment for parchment also from the perspective of conservation and not just as a recovery treatment.

Acknowledgements The parchment employed in this study has been produced, following traditional methods, by The National Research \& Development Institute for Textiles and Leather, ICPI Division, Ion Minulescu Street no. 93, 031215 Bucharest, Romania. M.M. thanks Barbara Sciardi for experimental help.

Author contributions MV designed the study and with CC contributed to the conception of experimental campaigns. MV performed the irradiation tests; CM and LS performed the FTIR spectroscopy; MM performed the UV-Vis-NIR spectroscopy; FM, UZ and NO performed the LTA analysis. MV and CC wrote the first draft of the manuscript; CM, MM, and FM wrote sections of the manuscript. All authors contributed to manuscript revision, read and approved the submitted version.

Funding Open access funding provided by Ente per le Nuove Tecnologie, l'Energia e l'Ambiente within the CRUI-CARE Agreement. M.M. and C.M. acknowledge funding from the National Research Council of Italy under the Project n. B86C19000230005 of the Joint Bilateral Agreement CNR/CACH Biennial Programme 2019-2021.

\section{Declarations}

Conflict of interest The authors declare that the research was conducted in the absence of any commercial or financial relationships that could be construed as a potential conflict of interest.

Open Access This article is licensed under a Creative Commons Attribution 4.0 International License, which permits use, sharing, adaptation, distribution and reproduction in any medium or format, as long as you give appropriate credit to the original author(s) and the source, provide a link to the Creative Commons licence, and indicate if changes were made. The images or other third party material in this article are included in the article's Creative Commons licence, unless indicated otherwise in a credit line to the material. If material is not included in the article's Creative Commons licence and your intended use is not permitted by statutory regulation or exceeds the permitted use, you will need to obtain permission directly from the copyright holder. To view a copy of this licence, visit http://creativecommons.org/licenses/by/4.0/.

\section{References}

1. M. Agati, The Manuscript Book, A Compendium of Codicology (L'Erma di Bretschneider, Roma, 2017)

2. C. Kennedy, T. Wess, Restaurator (2003). https://doi.org/10.1515/REST.2003.61

3. B. Haines, in Conservation of Leather and Related Materials, ed. by M. Kite, R. Thomson (Elsevier, Oxford, 2006), pp. 198-199

4. E. Hansen, S. Lee, H. Sobel, JAIC (1992). https://doi.org/10.1179/019713692806066600

5. M.C. Area, H. Cheradame, BioResources 6, 4 (2011)

6. J. Havermans, P. Marres, P. Defize, Restaurator (1999). https://doi.org/10.1515/rest.1999.20.1.48

7. R. Craig, Pap. Conserv. (1986). https://doi.org/10.1080/03094227.1986.9638528

8. F. Pinzari, V. Cialei, G. Piñar, in Historical Technology, Materials and Conservation: SEM and Microanalysis, ed. by N. Meeks, C. Cartwright, A. Meek, A. Mongiatti, (Archetype Publications, London, 2012), pp. 93-99.

9. G. Piñar, K. Sterflinger, J. Ettenauer, A. Quandt, F. Pinzari, Microb. Ecol. (2015). https://doi.org/10.1007/ s00248-014-0481-7

10. C. Cicero, F. Pinzari, F. Mercuri, Int. Biodet. Biodegr. (2018). https://doi.org/10.1016/j.ibiod.2018.08. 007 
11. F. Mercuri, P. Buonora, C. Cicero, P. Helas, F. Manzari, M. Marinelli, S. Paoloni, A. Pasqualucci, F. Pinzari, M. Romani, A. Terrei, O. Verdi, G. Verona Rinati, U. Zammit, N. Orazi, J. Cult. Herit. (2018). https://doi.org/10.1016/j.culher.2017.10.008

12. L. Migliore, M.C. Thaller, G. Vendittozzi, A. Mejia, F. Mercuri, S. Orlanducci, A. Rubechini, Sci. Rep. (2017). https://doi.org/10.1038/s41598-017-05398-7

13. L. Migliore, N. Perini, F. Mercuri, S. Orlanducci, A. Rubechini, M.C. Thaller, Sci. Rep. (2019). https:// doi.org/10.1038/s41598-018-37651-y

14. N. Valentin, Pap. Conserv. (1986). https://doi.org/10.1080/03094227.1986.9638530

15. M.C. Area, A.M. Calvo, F.E. Felissia, A. Docters, M.V. Miranda, Radiat. Phys. Chem. (2014). https:// doi.org/10.1016/j.radphyschem.2013.10.004

16. R. Kowalik, Restaurator (1980). https://doi.org/10.1515/rest.1980.4.3-4.135

17. M.G. Adamo, G. Magaudda, M. Plossi Zappalà, F. Rocchetti, G. Rossi, Restaurator (1998). https://doi. org/10.1515/rest.1998.19.1.41

18. M.G. Adamo, G. Magaudda, G. Martinelli, M. Plossi Zappalà, F. Rocchetti, F. Savagnone, Restaurator (2001). https://doi.org/10.1515/REST.2001.107

19. M. Da Silva, A.M.L. Moraes, M.M. Nishikawa, M.J.A. Gatti, M.A. Vallim de Alencar, L.E. Brandão, A. Nóbrega, Int. Biodet. Biodegr. (2006). https://doi.org/10.1016/j.ibiod.2006.02.003

20. G. Magaudda, J. Cult. Herit. (2014). https://doi.org/10.1016/j.culher.2003.07.003

21. M.L. Otero D’Almeida, P. Medeiros Barbosa, M.F. Guerra Boaratti, S.I. Borrely, Radiat. Phys. Chem. (2009). https://doi.org/10.1016/j.radphyschem.2009.03.032

22. C. Sendrea, E. Badea, I. Stãnculescu, L. Miu, H. Iovu, Revista de Pielarie Incaltaminte 15, 139-150 (2015)

23. C. Sendrea, C. Carşote, M. Radu, E. Badea, L. Miu, Rev. Chim. 68, 1535-1538 (2017)

24. I. Nunes, N. Mesquita, S. CaboVerde, M. Trigo, A. Ferreira, M.M. Carolino, A. Portugal, M.L. Botelho, Radiat. Phys. Chem. (2012). https://doi.org/10.1016/j.radphyschem.2012.07.016

25. M. Vadrucci, C. Cicero, F. Borgognoni, G. Ceres, N. Perini, L. Migliore, F. Mercuri, N. Orazi, S. Paoloni, A. Rubechini, in Metrology for Archaeology and Cultural Heritage (MetroArchaeo), Cassino FR, Italy, 2018, pp. 367-372, https://doi.org/10.1109/MetroArchaeo43810.2018.9089774

26. M. Vadrucci, F. Borgognoni, C. Cicero, N. Perini, L. Migliore, F. Mercuri, N. Orazi, A. Rubechini, Appl. Radiat. Isot. (2019). https://doi.org/10.1016/j.apradiso.2019.04.021

27. M. Vadrucci, C. Cicero, P. Parisse, L. Casalis, G. De Bellis, Appl. Surf. Sci. (2020). https://doi.org/10. 1016/j.apsusc.2020.145881

28. M. Vadrucci, G. De Bellis, C. Mazzuca, F. Mercuri, F. Borgognoni, E. Schifano, D. Uccelletti, C. Cicero, Front. Mater. (2020). https://doi.org/10.3389/fmats.2020.00021

29. M. Vadrucci, P. Ferrari, F. Borgognoni, L. Campani, Nucl. Instrum. Methods Phys. Res. A (2019). https:// doi.org/10.1016/j.nima.2019.02.066

30. C. Cicero, F. Mercuri, S. Paoloni, N. Orazi, U. Zammit, C. Glorieux, J. Thoen, Thermochim. Acta (2019). https://doi.org/10.1016/j.tca.2019.05.007

31. B. de CamposVidal, M.L.S. Mello, Micron (2011). https://doi.org/10.1016/j.micron.2010.09.010

32. K. Schwing, M. Gerhards, Int. Rev. Phys. Chem. (2016). https://doi.org/10.1080/0144235X.2016. 1229331

33. J. Kleinschmidt, in Methods in Molecular Biology (Methods and Protocols), ed. by J.M. Walker (Humana Press, Totowa, NJ, 2013), pp 177-218

34. G.M. Messina, B. Di Napoli, M. De Zotti, C. Mazzuca, F. Formaggio, A. Palleschi, G. Marletta, Langmuir (2019). https://doi.org/10.1021/acs.langmuir.8b03895

35. M. De Zotti, B. Muzzi, E. Gatto, B. Di Napoli, C. Mazzuca, A. Palleschi, E. Placidi, F. Formaggio, C. Toniolo, M. Venanzi, J. Phys. Chem. B (2018). https://doi.org/10.1021/acs.jpcb.8b01877

36. P.I. Haris, D. Chapman, Biopolymers (1995). https://doi.org/10.1002/bip.360370404

37. F. Mallamace, P. Baglioni, C. Corsaro, S.H. Chen, D. Mallamace, C. Vasi, H.E. Stanley, J. Chem. Phys. 10(1063/1), $4900500(2014)$

38. Y. Abe, S. Krimm, Biopolymers (1972). https://doi.org/10.1002/bip.1972.360110905

39. J.O. Alben, W.S. Caughey, Biochem. (1968). https://doi.org/10.1021/bi00841a022

40. M. Jackson, H.H. Mantsch, Crit. Rev. Biochem. Mol. Biol. (1995). https://doi.org/10.3109/ 10409239509085140

41. S. A. Tatulian, in Lipid-Protein Interactions: Methods and Protocols, ed. by J. H. Kleinschmidt, (Springer, New York, 2019) pp. 281-325

42. M. Missori, A. Mosca Conte, O. Pulci, L. Teodonio, S. Dominijanni, S. Puteo, S. Iannuccelli, S. Sotgiu, M.L. Sebastiani, Eur. Phys. J. Plus (2019). https://doi.org/10.1140/epjp/i2019-12524-3

43. G. Kortum, Reflectance Spectroscopy: Principles, Methods (Applications, Springer, Berlin, 1969)

44. B. Philips-Invernizzi, D. Dupont, C. Cazé, Opt. Eng. 10(1117/1), 1370387 (2001) 
45. M. Missori, Il Nuovo cimento C (2016). https://doi.org/10.1393/ncc/i2016-16293-x

46. M. Carbone, E. Bauer, L. Micheli, M. Missori, Colloids Surf. (2017). https://doi.org/10.1016/j.colsurfa. 2017.05.046

47. M. Missori, D. Pawcenis, J. Bagniuk, A. Mosca Conte, C. Violante, M.S. Maggio, M. Peccianti, O. Pulci, J. Łojewska, Microchem. J. (2018). https://doi.org/10.1016/j.microc.2018.06.010

48. P. Budrugeac, L. Miu, V. Bocu, F.J. Wortman, C. Popescu, J. Therm. Anal. (2003). https://doi.org/10. 1023/A: 1025007407683

49. E. Badea, L. Miu, P. Budrugeac, M. Giurginca, A. Mašić, N. Badea, G. Della Gatta, J. Therm. Anal. (2008). https://doi.org/10.1007/s10973-007-8513-x

50. E. Badea, G. Della Gatta, T. Usacheva, Polym. Degrad. Stab. (2012). https://doi.org/10.1016/j. polymdegradstab.2011.12.013

51. I. Petroviciu, C. Carsote, W. Wetter, L. Miu, M. Schreiner, 2014. Artificially aged parchment investigated by FTIR, in Third International Congress on Chemistry for Cultural Heritage 2014, Vienna, Austria

52. V. Plavan, M. Giurginca, P. Budrugeac, M. Vilsan, L. Miu, Rev. Chim. 61, 627-631 (2010)

53. G. Vyskočilová, M. Ebersbach, R. Kopecká, L. Prokeš, J. Príhoda, Heritage Sci (2019). https://doi.org/ 10.1186/s40494-019-0269-7

54. M. Bicchieri, M. Monti, G. Piantanida, A. Sodo M.T. Tanasi, Inside the parchment. (Proceedings of Art 2008 9th International Conference. 2008. p. 25-30, 2008.) https://www.ndt.net/article/art2008/papers/ 140Bicchieri.pdf Accessed 02 April 2021

55. Y. Maor, P. Shor, Z. Aizenshtat, Polym. Degrad. Stabil. (2020). https://doi.org/10.1016/j.polymdegradstab. 2020.109414

56. L. Miu, M. Giurginca, A. Meghea, Sci. Bull. B Chem. Mater. Sci. UPB 70, 51-56 (2008)

57. I.B. Lungu, V.I. Moise, M. Cutrubinis, I.R. Stanculescu, Study on mechanical propreties of gamma irradiated leather and parchment. (Proceedings of the 5th ICAMS 2014, $23-25$ October 2014, 527-532, 2014) http://icams.ro/icamsresurse/2014/full_papers/5_Cultural_Heritage/05.pdf Accessed 02 April 2021

58. F. Cappa, I. Paganoni, C. Carsote, M. Schreiner, E. Badea, Polym. Degrad. Stab. (2020). https://doi.org/ 10.1016/j.polymdegradstab.2020.109375

59. M. Odlyha, C. Theodorakopoulos, J. de Groot, L. Bozec, H. Horton, e-PS 6, 138-144 (2009)

60. C.A. Miles, A. Sionkowska, S.L. Hulin, T.J. Sims, N.C. Avery, A.J. Bailey, J. Biol. Chem. (2000). https:// doi.org/10.1074/jbc.M002346200 